\title{
Scan-display of high-resolution images using the Apple II
}

\author{
JACK M. LOOMIS \\ University of California, Santa Barbara, California
}

\begin{abstract}
Two programs are presented for the scan-display of high-resolution images using the Apple II+ and Apple IIe. The first program permits the user to move a rectangular aperture about the video screen to reveal different portions of a stationary image. The second program scrolls an image vertically within a horizontal window, giving rise to the impression of an object moving behind a stationary slit. These programs should be useful in the study of anorthoscopic perception, motion perception, perceptual integration of successively displayed information, and other topics in visual perception.
\end{abstract}

This paper presents two programs incorporating machine-language routines for scan-display of highresolution (HIRES) images on the Apple II+ and Apple IIe. The first program, APERTURE, permits the user to move a rectangular aperture about the video screen, thus revealing different portions of a stationary image stored in memory; movement of the aperture "in front of" the image is controlled by the Apple paddle inputs. The second program, ANORTHOSCOPIC, scrolls an image vertically within a narrow horizontal window, giving rise to the impression of an object moving behind a stationary slit. This progam was designed for use in the study of anorthoscopic perception (Anstis \& Atkinson, 1967; Parks, 1965; Rock, 1981).

The two BASIC program listings are given in Tables 1 and 2. The machine language routine for each is stored in the data statements beginning at line 500 and is POKEd into memory in line 10 . For both programs, the image being scanned is stored in Page 2 of HIRES screen memory (\$4000-\$5999) and is displayed on Page 1 $(\$ 2000-\$ 3999)$. Because successive rows of the Apple video screen are not represented sequentially in screen memory, the scanning routines make use of lookup tables to optimize speed. Table 3 lists the BASIC program (LOOKUP) that computes the lookup tables for HIRES Pages 1 and 2 and stores them beginning at $\$ 6000$. (APERTURE uses only the table for Page 2.)

To avoid beat-like interaction (aliasing) between the graphical output of the Apple and the video frame rate $(59.92 \mathrm{~Hz}$ in the American Apple and $50.32 \mathrm{~Hz}$ in the Eurapple; see Sather, 1983), each machine language routine synchronizes output to the video blanking signal. Synchronization has been described in earlier articles (Cavanagh \& Anstis, 1980; Diener \& Smee, 1984; Reed, 1979). For the Apple IIe the vertical blanking signal is

The author thanks Michael Swanston and Richard Parker for their help and encouragement. The author's mailing address is: Department of Psychology, University of California, Santa Barbara, CA 93106.
Table 1

APERTURE Program

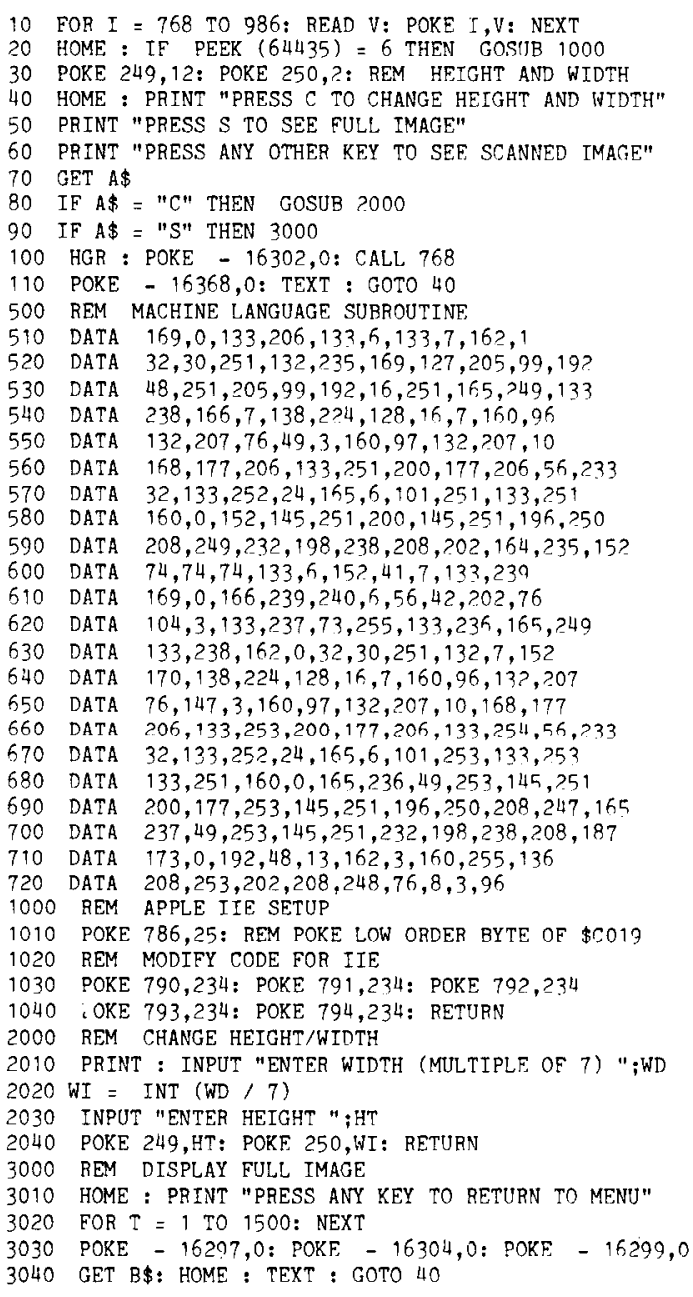

accessible to software at decimal address 49177 (\$C019). As described in Cavanagh and Anstis (1980) and Reed (1979), this signal can be made accessible at memory location 49251 ( $\$ C 063)$ in the Apple II+ by connecting a jumper cable between Pin 8 of integrated circuit socket 
Table 2 ANORTHOSCOPIC Program

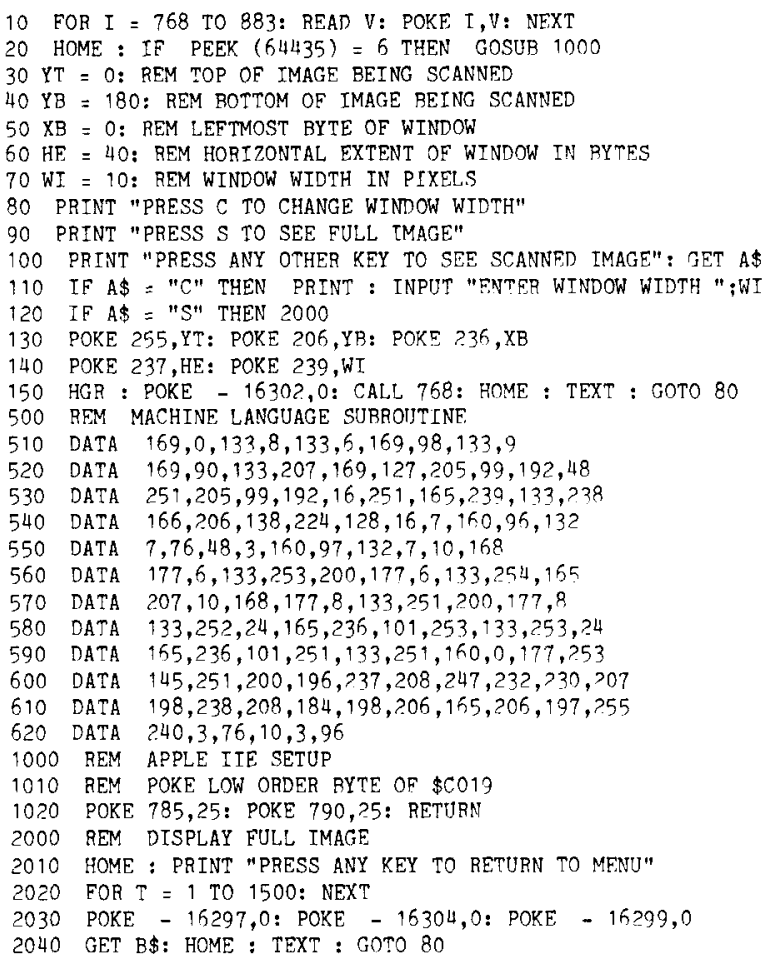

Table 3

LOOKUP Program

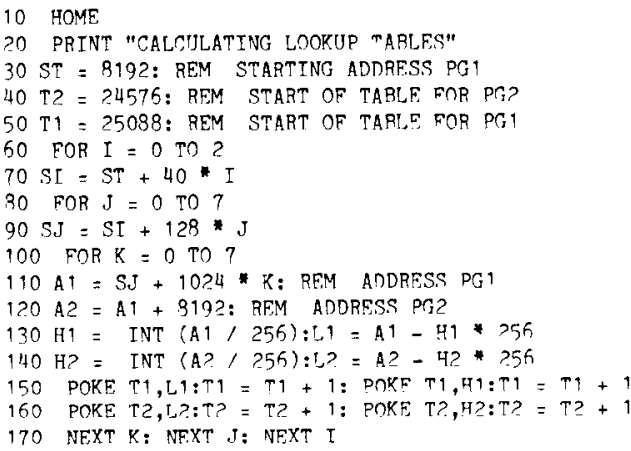

B11 and Pin 4 of socket J14 (the game I/O connector). The machine language subroutines are written for the Apple II+; if an Apple IIe is used, the setup subroutine beginning at line 1000 in each program POKEs the appropriate memory location into the machine language routines (as well as modifying the code in the aperture routine).

\section{EXPLICATION OF MACHINE CODE ROUTINES}

The source listings for the two machine code routines are given in Tables 4 and 5. Both routines make extensive use of available zero page locations. The APERTURE routine has two main sections. During each cycle, one section (lines 66-139) transfers a small portion of the stored image in Page 2 into Page 1 for display. The other section (lines 32-65) erases the previously displayed portion. Ancillary sections initialize the routine, determine the paddle values, and wait for the video scan blanking pulse (lines 25-29). The two paddle values are read in separate sections of the routine to minimize their interaction. An explication of the main transfer section follows.

Beginning in line 67, the routine reads the value of PDL(1), which represents the horizontal or $X$ value of the left edge of the aperture. This $X$ value is divided by 8 to determine at which of the 32 bytes in the X dimension the aperture is located. This value is called XBYTE and is later added to the address of the leftmost byte in that row. The same PDL(1) value is then ANDed with $\$ 07$ to find the three least significant bits. These bits indicate where the position being indicated by PDL(1) is within XBYTE. The resulting value is called PREMASK. It is used to create RMASK and LMASK, the respective masks for the rightmost and leftmost bytes defining the aperture. LMASK and RMASK are fixed for a given scan of the aperture, because the sides of the aperture are vertical. They are therefore determined before the scanning of the image begins. The same is true of the determination of the uppermost position of the aperture, which is controlled by PDL( 0$)$, which represents the $Y$ dimension. This value is placed in the $\mathrm{X}$ register.

For each image frame, transfer and display of the image occurs row by row and, within each row, column by column. For each row scan, the value of the $X$ register is transferred to the $\mathrm{Y}$ register and then doubled as an offset in the indirect, indexed mode to determine the address of the leftmost position of that row from the lookup table. The address returned is the Page 2 address; the corresponding Page 1 address is obtained by subtracting $\$ 20$ from the high-order byte. The next step is to find the starting address within the row that corresponds to the leftmost position of the aperture; this is accomplished by adding XBYTE to the starting address of that row and storing this result. At this point scanning of the image columnby-column within the top row begins. The first byte of the stored pattern (in Page 2) is ANDed with LMASK to determine which bits will be turned on, and the masked byte is moved to Page 1 . Next the middle bytes of the scanned image are simply moved from Page 2 to Page 1 , and then the rightmost byte is masked by RMASK and moved to Page 1 . With this row completed, the $Y$ value on the screen (contained in the $\mathrm{X}$ register) is incremented and scanning of the next row begins.

The structure of the ANORTHOSCOPIC routine is much simpler. Because the displayed image has a constant screen position from one frame to the next, no erase section is required. In addition, only whole bytes are moved from Page 2 to Page 1, so that no masks are utilized. Furthermore, the starting $\mathrm{Y}$ value of each frame is obtained by decrementing Y2BOT rather than by reading a paddle. The only way in which the routine is more complex than the APERTURE routine is that the $Y$ value of the image being scanned (Y2BOT) is not the same as 
Table 4

Source Listing of APERTURE Routine

\begin{tabular}{|c|c|c|c|c|c|c|}
\hline 0300: & & 1 & & ORG & $\$ 300$ & \\
\hline FBIE: & & 2 & PADDLE & EQU & \$FB1E & \\
\hline C000: & & 3 & STROBE & EQU & $\$ C 000$ & \\
\hline OOFB: & & 4 & PG1LO & EQU & $\$ F B$ & \\
\hline OOFC: & & 5 & PG1HI & EQU & $\$ F C$ & \\
\hline OOFD: & & 6 & PG2LO & EQU & \$FD & \\
\hline OOFE: & & 7 & PG2HI & EQU & $\$ F E$ & \\
\hline OOCE: & & 8 & LOOKL & $E Q U$ & $\$ C E$ & \\
\hline OOCF: & & 9 & LOOKH & $\mathrm{EQU}$ & $\$ C F$ & \\
\hline OOF9: & & 10 & HEIGHT & EQU & $\$ F 9$ & \\
\hline OOFA: & & 11 & WIDTH & EQU & $\$ F A$ & \\
\hline 0006: & & 12 & XBYTE & $\mathrm{EQU}$ & $\$ 06$ & \\
\hline 0007: & & 13 & YVAL & EQU & $\$ 07$ & \\
\hline OOEB: & & 14 & PDL 1 & EQU & $\$ \mathrm{~EB}$ & \\
\hline OOEC: & & 15 & LMASK & EQU & $\$ \mathrm{EC}$ & \\
\hline OOED: & & 16 & RMASK & EQU & $\$ E D$ & \\
\hline OOEE: & & 17 & ROW & EQU & $\$ E E$ & \\
\hline OOEE: & & 18 & PREMASK & EQU & $\$ E F$ & \\
\hline $0300: A 9$ & 00 & 19 & & LDA & $\# \$ 00$ & \\
\hline $0302: 85$ & $C E$ & 20 & & STA & LOOKL & \\
\hline $0304: 85$ & 06 & 21 & & STA & XBYTE & \\
\hline $0306: 85$ & 07 & 22 & & STA & YVAL & \\
\hline $0308: A 2$ & 01 & 23 & START & LDX & $\$ \$ 01$ & \\
\hline $030 \mathrm{~A}: 20$ & $1 E F B$ & 24 & & JSR & PADDLE & \\
\hline $030 D: 84$ & $E B$ & 25 & & STY & PDL1 & ; HORI7 PADDLE \\
\hline O30F:A9 & $7 F$ & 26 & & LDA & $\# \$ 7 F$ & \\
\hline $0311: C D$ & $63 \mathrm{Co}$ & 27 & LOOP1 & CMP & $\$ C 063$ & \\
\hline $0314: 30$ & FB & 28 & & BMI & LOOP 1 & \\
\hline $0316: C D$ & $63 \mathrm{Co}$ & 29 & LOOP2 & CMP & $\$ C 063$ & \\
\hline $0319: 10$ & FB & 30 & & BPL & LOOP2 & \\
\hline 031B: & & 31 & - ERASE & OLD IM & MAGE & \\
\hline 031B:A5 & F9 & 32 & & LDA & HEIGHT & \\
\hline $0310: 85$ & $\mathrm{EE}$ & 33 & & STA & ROW & \\
\hline $031 \mathrm{~F}: \mathrm{A} 6$ & 07 & 34 & & LDX & YVAL & \\
\hline $0321: 8 \mathrm{~A}$ & & 35 & ERWLOOP & TXA & & \\
\hline $0322: \mathrm{EO}$ & 80 & 36 & & CPX & $\$ \$ 80$ & ;YVAL> $127 ?$ \\
\hline $0324: 10$ & 07 & 37 & & BPL & EOVER & \\
\hline $0326: A 0$ & 60 & 38 & & LDY & $\$ \$ 60$ & \\
\hline $0328: 84$ & $C F$ & 39 & & STY & LOOKH & \\
\hline $032 \mathrm{~A}: 4 \mathrm{C}$ & 3103 & 40 & & JMP & EMULT & \\
\hline 032D:A0 & 61 & 41 & EOVER & LDY & $\$ 61$ & \\
\hline $032 F: 84$ & $\mathrm{CF}$ & 42 & & STY & LOOKH & \\
\hline $0331: 0 A$ & & 43 & EMULT & ASL & A & ;MULT X 2 \\
\hline $0332: A 8$ & & 44 & & TAY & & \\
\hline $0333: \mathrm{B} 1$ & $C E$ & 45 & & LDA & (LOORL), Y & ; LOWBYTE \\
\hline $0335: 85$ & $\mathrm{FB}$ & 46 & & STA & PGILO & \\
\hline $0337: C 8$ & & 47 & & INY & & \\
\hline $0338: \mathrm{B} 1$ & $\mathrm{CE}$ & 48 & & LDA & (LOOKL), Y & ; HIGHBYTE \\
\hline $033 A: 38$ & & 49 & & SEC & & \\
\hline O33B:E9 & 20 & 50 & & SBC & $\$ \$ 20$ & \\
\hline $0330: 85$ & FC & 51 & & STA & PG 1HI & \\
\hline $033 \mathrm{~F}: 18$ & & 52 & & CLC & & \\
\hline $0340: A 5$ & 06 & 53 & & LDA & XBYTE & \\
\hline $0342: 65$ & FB & 54 & & $A D C$ & PGILO & ;STARTBYTE \\
\hline $0344: 85$ & FB & 55 & & STA & PGILO & \\
\hline $0346: A 0$ & 00 & 56 & & LDY & $\$ \$ 00$ & \\
\hline $0348: 98$ & & 57 & & TYA & & \\
\hline $0349: 91$ & FB & 58 & & STA & (PG1LO), Y & ; ERASE \\
\hline $034 \mathrm{~B}: \mathrm{C} 8$ & & 59 & ECLLOOP & $I N Y$ & & \\
\hline $034 \mathrm{C}: 91$ & FB & 60 & & STA & $(P G 1 L O), Y$ & ;ERASE \\
\hline $034 \mathrm{E}: \mathrm{CH}$ & FA & 61 & & CPY & WIDTH & \\
\hline $0350: D 0$ & F9 & 62 & & BNE & ECLLOOP & \\
\hline $0352: E 8$ & & 63 & & INX & & ; INCREMENT YVAL \\
\hline $0353: C 6$ & $\mathrm{EE}$ & 64 & & DEC & ROW & \\
\hline $\begin{array}{l}\text { 0355:D0 } \\
\text { 0357: }\end{array}$ & $\mathrm{CA}$ & $\begin{array}{l}65 \\
66\end{array}$ & SCAN P & $\begin{array}{l}\text { BNE } \\
\text { ICTURE }\end{array}$ & ERWLOOP & \\
\hline $0357: A 4$ & EB & 67 & & LDY & PDL 1 & ; HORIZ PADDLE \\
\hline $0359: 98$ & & 68 & & TYA & & \\
\hline $035 \mathrm{~A}: 4 \mathrm{~A}$ & & 69 & & LSR & A & ;DIVIDE BY 8 \\
\hline $035 \mathrm{~B}: 4 \mathrm{~A}$ & & 70 & & LSR & A & \\
\hline $035 \mathrm{C}: 4 \mathrm{~A}$ & & 71 & & LSR & A & \\
\hline 035D: 85 & 06 & 72 & & STA & XBYTE & \\
\hline $035 F: 98$ & & 73 & & TYA & & \\
\hline $0360: 29$ & 07 & 74 & & AND & $\$ \$ 07$ & ; 3 LS BITS \\
\hline $0362: 85$ & $E F$ & 75 & & STA & PREMASK & \\
\hline $0364: A 9$ & 00 & 76 & & LDA & $\$ \$ 00$ & \\
\hline $0366: A 6$ & $E F$ & 77 & & LDX & PREMASK & \\
\hline $0368: \mathrm{FO}$ & 06 & 78 & SHIFT & $\mathrm{BEQ}$ & MASKS & \\
\hline $036 \mathrm{~A}: 38$ & & 79 & & SEC & & \\
\hline $036 \mathrm{~B}: 2 \mathrm{~A}$ & & 80 & & ROL & A & \\
\hline $036 \mathrm{C}: \mathrm{CA}$ & & 81 & & DEX & & \\
\hline $036 \mathrm{D}: 4 \mathrm{C}$ & $\begin{array}{ll}68 & 03\end{array}$ & 82 & & JMP & SHIFT & \\
\hline $0370: 85$ & ED & 83 & MASKS & STA & RMASK & ; RIGHT MASK \\
\hline
\end{tabular}

\begin{tabular}{|c|c|c|c|c|c|c|}
\hline $0372: 49$ & $\mathrm{FF}$ & 84 & & EOR & $\# \$ F F$ & ;FIND INVERSE \\
\hline $0374: 85$ & EC & 85 & & STA & LMASK & ; LEFT MASK \\
\hline $0376: A 5$ & F9 & 86 & & LDA & HEIGHT & \\
\hline $0378: 85$ & $\mathrm{EE}$ & 87 & & STA & ROW & \\
\hline $037 \mathrm{~A}: \mathrm{A} 2$ & 00 & 88 & & LDX & $\$ \$ 00$ & \\
\hline $037 \mathrm{C}: 20$ & $1 \mathrm{E} \mathrm{FB}$ & 89 & & JSR & PADDLE & \\
\hline $037 F: 84$ & 07 & 90 & & STY & YVAL & ; VERT PADDLF \\
\hline $0381: 98$ & & 91 & & TYA & & \\
\hline 0382:AA & & 92 & & TAX & & ;YVAL IN X REG \\
\hline $0383: 8 \mathrm{~A}$ & & 93 & ROWLOOP & TXA & & \\
\hline $0384: E 0$ & 80 & 94 & & $\mathrm{CPX}$ & $\$ \$ 80$ & ;YVAL $>127 ?$ \\
\hline $0386: 10$ & $0 ?$ & 95 & & BPL & OVER & \\
\hline $0388: A 0$ & 60 & 96 & & LDY & $\$ \$ 60$ & \\
\hline $038 \mathrm{~A}: 84$ & $\mathrm{CE}$ & 97 & & STY & LOOKH & \\
\hline $038 \mathrm{C}: 4 \mathrm{C}$ & 9303 & 98 & & JMP & MULTIPL & \\
\hline $038 \mathrm{~F}: \mathrm{AO}$ & 61 & 99 & OVER & LDY & $\$ \$ 61$ & \\
\hline $0391: 84$ & $\mathrm{CF}$ & 100 & & STY & LOOKH & \\
\hline $0393: 0 \mathrm{~A}$ & & 101 & MULTIPL & ASL & A & ;MULT X ? \\
\hline $0394: 188$ & & 102 & & TAY & & \\
\hline $0395: \mathrm{B1}$ & $C E$ & 103 & & LDA & (LOOKL), Y & ; LOWBYTE \\
\hline $0397: 85$ & FD & 104 & & STA & PG?LO & \\
\hline $0399: C 8$ & & 105 & & INY & & \\
\hline $039 \mathrm{~A}: \mathrm{B1}$ & $C E$ & 106 & & LDA & (LOOKL), Y & ; HIGHBYTE \\
\hline $0390: 85$ & $\mathrm{FE}$ & 107 & & STA & PGPHI & \\
\hline $039 E: 38$ & & 108 & & SEC & & \\
\hline O39F:E9 & 20 & 109 & & SBC & $\# \$ 20$ & \\
\hline $03 A 1: 85$ & FC & 110 & & STA & PG1HI & \\
\hline $03 A 3: 18$ & & 111 & & CLC & & \\
\hline $03 A 4: A 5$ & 06 & 112 & & LDA & XBYTE & \\
\hline $03 A 6: 65$ & FD & 113 & & $A D C$ & PG2LO & ;STARTBYTE \\
\hline $03 A 8: 85$ & FD & 114 & & STA & PG2LO & \\
\hline $03 A A: 85$ & FB & 115 & & STA & PG1LO & \\
\hline $03 \mathrm{AC}: \mathrm{AO}$ & 00 & 116 & & LDY & $\$ \$ 00$ & \\
\hline O3AE:A5 & EC & 117 & & LDA & LMASK & \\
\hline $03 \mathrm{~B} 0: 31$ & FD & 118 & & AND & $(\mathrm{PG} L \mathrm{LO}), \mathrm{Y}$ & ;MASK BYTE \\
\hline 03B2: 91 & FB & 119 & & STA & $(P G 1 L O), Y$ & ;DISPLAY LEFT BYTE \\
\hline $03 B 4: C 8$ & & 120 & COLLOOP & INY & & \\
\hline 03E5: B1 & FD & 121 & & LDA & (PGLLO), $Y$ & \\
\hline $03 B 7: 91$ & FB & 122 & & STA & (PG1LO), Y & ;DISPLAY MTDDLE \\
\hline $03 \mathrm{~B} 9: \mathrm{C} 4$ & FA & 123 & & $C P Y$ & WIDTH & \\
\hline 03BB:DO & F7 & 124 & & BNE & COLLOOP & \\
\hline $03 \mathrm{BD}: \mathrm{A} 5$ & ED & 125 & & LDA & RMASK & \\
\hline O3BE: 31 & FD & 126 & & AND & (PG2LO), Y & ;MASK BYTE \\
\hline $03 \mathrm{C} 1: 91$ & FB & 127 & & STA & (PG1LO),Y & ;DISPLAY RIGHT BYTE \\
\hline $03 C 3: E 8$ & & 128 & & INX & & ; INCREMENT YVAL \\
\hline $03 \mathrm{C} 4: \mathrm{C} 6$ & EE & 129 & & DEC & ROW & \\
\hline 03C6:D0 & BB & 130 & & BNE & ROWLOOP & \\
\hline $03 \mathrm{C} 8: \mathrm{AD}$ & $00 \mathrm{CO}$ & 131 & & LDA & STROBE & \\
\hline $03 \mathrm{CB}: 30$ & $O D$ & 132 & & BMI & RETURN & \\
\hline $03 C D: A 2$ & 03 & 133 & & LDX & $\$ \$ 03$ & \\
\hline OSCF:A0 & $\mathrm{FF}$ & 134 & DELAY 1 & LDY & $\# \$ F F$ & \\
\hline $03 \mathrm{D} 1: 88$ & & 135 & DELAY 2 & DEY & & \\
\hline 03D2:D0 & FD & 136 & & BNE & DELAY2 & \\
\hline $0304: C A$ & & 137 & & DEX & & \\
\hline 03D5:D0 & F8 & 138 & & BNE & DELAY 1 & \\
\hline $03 \mathrm{D} 7: 4 \mathrm{C}$ & 0803 & 139 & & JMP & START & \\
\hline $03 \mathrm{DA}: 60$ & & 140 & RETURN & RTS & & ; TO BASTC \\
\hline
\end{tabular}

the top of the display window (Y1) on Page 1, so that the lookup table must be consulted separately for each page for every row that is scanned.

\section{USER INSTRUCTIONS}

The procedure for using either program is simple. (Apple IIe users can proceed directly; Apple II+ users need to first install the jumper cable.) The sequence of steps is to run LOOKUP, load the HIRES image into Page 2, and then run whichever program is desired. The command for loading an image labeled PIC.1 into Page 2 is BLOAD PIC.1,A $\$ 4000$. After the lookup table is created for the first time by running LOOKUP, the table can be saved to disk using BSAVE TABLE,A $\$ 6000, \mathrm{~L} \$ 400$. On subsequent occasions the setup time can be shortened by typing BLOAD TABLE rather than by running LOOKUP. 
Table 5

Source Listing of ANORTHOSCOPIC Routine

\begin{tabular}{|c|c|c|c|c|c|c|c|}
\hline 0300: & & & 1 & & ORG & $\$ 300$ & \\
\hline OOFB: & & & 2 & PG १LO & EQU & $\$ F B$ & \\
\hline OOFC: & & & 3 & $P G 1 \mathrm{HI}$ & EQU & $\$ F C$ & \\
\hline OOFD: & & & 4 & $\mathrm{PG} \geq \mathrm{LO}$ & EQU & $\$ E D$ & \\
\hline OOEE: & & & 5 & PG $2 \mathrm{HI}$ & EQU & $\$ F E$ & \\
\hline 0006: & & & 6 & LOOKL? & EQU & $\$ 06$ & \\
\hline 0007: & & & 7 & LOOKH2 & EQU & $\$ 07$ & \\
\hline $0008:$ & & & 8 & LOOKL 1 & $\mathrm{EQU}$ & $\$ 08$ & \\
\hline 0009: & & & 9 & LOOKH 1 & EQU & $\$ 09$ & \\
\hline OOFF: & & & 10 & Y2TOP & EQU & \$EF & \\
\hline OOCE: & & & 11 & Y2BOT & EQU & $\$ C E$ & \\
\hline OOCF: & & & 12 & Y1 & EQU & $\$ C F$ & \\
\hline OOEC: & & & 13 & XBYTE & EQU & $\$ C C$ & \\
\hline OOED: & & & 14 & WIDTH & EQU & \$ED & \\
\hline OOEE: & & & 15 & ROW & EQU & \$EE & \\
\hline DOEF: & & & 16 & HEIGHT & EQU & $\$ E F$ & \\
\hline $0300: A 9$ & 00 & & 17 & & LDA & $\$ \$ 00$ & \\
\hline $0302: 85$ & 08 & & 18 & & STA & LOOKL 1 & \\
\hline $0304: 85$ & 06 & & 19 & & STA & LOOKL? & \\
\hline $0306: A 9$ & 62 & & 20 & & CDA & $\$ \$ 52$ & \\
\hline $0308: 85$ & 09 & & 21 & & STA & LOOKH 1 & \\
\hline 030A:A9 & $5 \mathrm{~A}$ & & 22 & START & LDA & $\# \$ 5 A$ & \\
\hline $030 \mathrm{C}: 85$ & $C F$ & & 23 & & STA & $Y \uparrow$ & \\
\hline O3OE:A9 & $7 F$ & & 24 & & LDA & $\$ \$ 7 F$ & \\
\hline $0310: C D$ & 63 & $\mathrm{CO}$ & 25 & LOOP1 & CMP & $\$ 0063$ & \\
\hline $0313: 30$ & FB & & 26 & & BMI & LOOP1 & \\
\hline $0315: C D$ & 63 & $\mathrm{CO}$ & 27 & LOOP2 & CMP & $\$ C 063$ & \\
\hline $0318: 10$ & EB & & 28 & & BPL & LOOP? & \\
\hline 031A:A5 & EF & & 29 & & LDA & HE.IGHT & \\
\hline $031 \mathrm{C}: 85$ & $\mathrm{EE}$ & & 30 & & STA & ROW & \\
\hline 031E:A6 & $C E$ & & 31 & & LDX & $\mathrm{Y} \geq \mathrm{BOT}$ & ;Y2 IN X REG \\
\hline $0320: 8 \mathrm{~A}$ & & & 32 & ROWLOOP & TXA & & \\
\hline $0321: \mathrm{EO}$ & 80 & & 33 & & $C P X$ & $\$ \$ 80$ & ; $\mathrm{Y} 2) 127 ?$ \\
\hline $0323: 10$ & 07 & & 34 & & BPL & OVER & \\
\hline $0325: A 0$ & 60 & & 35 & & LDY & $\$ \$ 60$ & \\
\hline $0327: 84$ & 07 & & 36 & & STY & LOOKH2 & \\
\hline $0329: 4 \mathrm{C}$ & 30 & 03 & 37 & & JMP & MULTIPL & \\
\hline $032 \mathrm{C}: \mathrm{AO}$ & 61 & & 38 & OVER & LDY & $\$ \$ 61$ & \\
\hline $032 \mathrm{E}: 84$ & 07 & & 39 & & STY & LOOKH? & \\
\hline $0330: 0 \mathrm{~A}$ & & & 40 & MULTIPL & ASL & A & ;MULT X 2 \\
\hline $0331: A 8$ & & & 41 & & TAY & & \\
\hline 0332: B1 & 06 & & 42 & & LDA & $($ LOOKL2), $\mathrm{Y}$ & i ;LOWBYTE PG? \\
\hline $0334: 85$ & FD & & 43 & & STA & PG2LO & \\
\hline $0336: C 8$ & & & 44 & & INY & & \\
\hline $0337: B 1$ & 06 & & 45 & & LDA & $($ LOOKL2), $\mathrm{Y}$ & ; HIGHBYTE PG2 \\
\hline $0339: 85$ & FE & & 46 & & STA & PGPHI & \\
\hline $033 \mathrm{~B}: \mathrm{A5}$ & $\mathrm{CF}$ & & 47 & & LDA & $Y 1$ & \\
\hline $033 \mathrm{D}: 0 \mathrm{~A}$ & & & 48 & & ASL & A & ;MULT X 2 \\
\hline $033 E: A 8$ & & & 49 & & TAY & & \\
\hline $033 \mathrm{~F}: \mathrm{B1}$ & 08 & & 50 & & LDA & (LOOKL 1), Y & I ;LOWBYTE PG1 \\
\hline $0341: 85$ & FB & & 51 & & STA & PG1LO & \\
\hline $0343: c 8$ & & & 52 & & INY & & \\
\hline $\begin{array}{l}0344: B 1 \\
0346: 85\end{array}$ & $\begin{array}{l}08 \\
\text { EC }\end{array}$ & & $\begin{array}{l}53 \\
54\end{array}$ & & $\begin{array}{l}\text { LDA } \\
\text { STA }\end{array}$ & $\begin{array}{l}\text { (LOOKL 1),Y } \\
\text { PG1HI }\end{array}$ & ; ;HIGHBYTE PG 1 \\
\hline $0348: 18$ & & & 55 & & CLC & & \\
\hline $0349: A 5$ & $\mathrm{EC}$ & & 56 & & LDA & XBYTE & \\
\hline $034 \mathrm{~B}: 55$ & ED & & 57 & & ADC & PG2LO & ; STARTBYTE PG? \\
\hline $0340: 85$ & FD & & 58 & & STA & PGZLO & \\
\hline $034 \mathrm{~F}: 18$ & & & 59 & & CLC & & \\
\hline $0350: A 5$ & EC & & 60 & & LDA & XBYTE & \\
\hline $0352: 65$ & FB & & 61 & & $A D C$ & PG1LO & ;STARTBYTE PG 1 \\
\hline $0354: 85$ & EB & & 62 & & STA & PG 1LO & \\
\hline 0356:A0 & 00 & & 63 & & LDY & $\$ \$ 00$ & \\
\hline $0358: 81$ & ED & & 64 & COLLOOP & LDA & (PGLLO),Y & \\
\hline $035 A: 91$ & $\mathrm{FB}$ & & 65 & & STA & (PG1LO),Y & ;TRANSFER IMAGE \\
\hline $035 \mathrm{C}: \mathrm{C} 8$ & & & 66 & & INY & & \\
\hline $035 D: C 4$ & ED & & 67 & & CPY & WIDTH & \\
\hline $035 F: D 0$ & 57 & & 68 & & BNE & COLLOOP & \\
\hline $0361: E 8$ & & & 69 & & INX & & ; INCREMENT Y2 \\
\hline $0362: E 6$ & $\mathrm{CF}$ & & 70 & & INC & Y1 & ; INCREMFNT Y1 \\
\hline $0364: C 6$ & EE & & 71 & & DEC & ROW & \\
\hline 0366:D0 & 88 & & 72 & & BNE, & ROWLOOP & \\
\hline $0368: c 6$ & $\mathrm{CE}$ & & 73 & & DEC & Y2BOT & \\
\hline O36A:A5 & $\mathrm{CE}$ & & 74 & & LDA & Y2BOT & \\
\hline $036 \mathrm{C}: \mathrm{C} 5$ & FF & & 75 & & CMP & YгTOP & \\
\hline $036 \mathrm{E}: \mathrm{FO}$ & 03 & & 75 & & $B E Q$ & RETURN & \\
\hline $0370: 4 \mathrm{C}$ & $D A$ & 03 & 77 & & JMP & START & \\
\hline $0373: 60$ & & & 78 & RETURN & RTS & & ; TO BASIC \\
\hline
\end{tabular}

\section{LIMITATIONS}

The Apple HIRES screen is 280 pixels wide $\times$ 192 pixels high for black-and-white images. The APER-
TURE program permits the user to select the height and width of the aperture; height can be varied in steps of 1 , but the width variable is limited to multiples of 7 , because each row scan involves sequencing through an integral number of bytes. (Only 7 horizontal pixels on the display screen are represented by each byte of display memory; the high-order bit is not displayed.) Smooth high-speed scanning of an image is possible for apertures up to a size of about 28 pixels $\times 28$ pixels. Replacing the one-shot paddle timing with true analog-to-digital conversion should permit smooth scanning with still larger apertures. Whatever the size limit, portions of the displayed image near the top of the screen are distorted for large apertures because of the time it takes to erase the old displayed image and redraw the new one following the vertical blanking signal. Another minor limitation of the routine is that the leftmost edge of the aperture has a maximum value of 255 , corresponding to the value of Paddle 1; for small aperture widths, this means that the rightmost portion of the Apple screen (values close to 279) will not be displayed. Finally, multicolored images can be displayed using the program, but there will be some color distortion near the sides of the aperture.

The ANORTHOSCOPIC program was written for vertical scrolling within a horizontal window rather than for horizontal scrolling within a vertical window because the former permits faster scrolling. Because the graphic output is synchronized to the video frame rate, images are scrolled vertically at the rate of 59.92 rows/sec $(50.32$ rows/sec for the Eurapple). This scrolling rate remains constant for window widths in the vertical dimension ranging from 1 to 19 pixels when a window extending across the screen is used. Using narrower horizontal extents permits larger vertical extents for the same scrolling rate. Consequently, the program is quite useful for precisely controlled investigations of anorthoscopic perception. For those familiar with assembly language programming, the routine can be modified to allow multiple windows on the screen (e.g., for stereoscopic presentation), control of the image scanning using paddles, and movement of the display window concomitant with scan of the stored image. Multicolored images can be displayed without distortion.

\section{APPLICATIONS}

The potential uses of APERTURE are varied. One application is to use a graphics touch tablet to control the aperture, using the finger in a visual simulation of tactual exploration. Similarly, driving the aperture locations with suitable eye-monitoring equipment would provide a simple method of controlling field-of-view during visual exploration. Finally, aperture scanning, whether controlled by eye movements, joystick, graphics tablet, or Space Pen (Soniture, Inc.), could be useful in investigating the perceptual integration of sequentially sampled information (Hochberg, 1978) and for determining which spatial features are most critical in visual illusions, pattern perception, and depiction of three-dimensional objects. An advantage of using the computer over some of 
the traditional methods for studying these questions is that the path of the scanning aperture can be made available for analysis with very little additional programming effort.

One application of ANORTHOSCOPIC is in the investigation of anorthoscopic perception. In pilot work, the program has proven highly satisfactory. One advantage of computer control over conventional methods is that the window width can easily be made "infinitesimally narrow" (in this case, 1 pixel) so that information about direction of image motion (upward or downward) and local line orientation, information that is normally available in windows of finite width (more than 1 pixel), can be eliminated. Another advantage is that the remainder of the graphics screen can be manipulated independently of the scanned image, using machine language or the graphics commands of Applesoft BASIC. Aside from the study of anorthoscopic perception, another potential application of this program is in investigation of the "aperture problem"' in the context of motion perception (Adelson \& Movshon, 1982; Hildreth, 1984; Marr, 1982; Nakayama, 1985). A virtue of using this type of program to "move" the stored image in Page 2, rather than programming the moving patterns using the graphics primitives of, say, Applesoft, is that the image velocity within the window is completely independent of pattern complexity.

Researchers who do not wish to create their own highresolution images are referred to Prill (1984). Prill has created Apple HIRES images of 73 of the 260 drawings of familiar objects developed by Snodgrass and Vanderwart (1980), for which there are a number of normative ratings. These 73 pictures, together with a number of image manipulation programs, are available from Prill for a nominal charge (K. A. Prill, Department of Psychology, University of Missouri, Columbia MO 65211).

\section{REFERENCES}

Adelson, E. H., \& Movshon, J. A. (1982). Phenomenal coherence of moving visual patterns. Nature, 300, 523-525.

Anstis, S. M., \& ATKINSON, J. (1967). Distortions in moving figures viewed through a stationary slit. American Journal of Psychology, 80, 572-585.

CAvanaGH, P., \& ANSTIS, S. M. (1980). Visual psychophysics on the APPLE II: Getting started. Behavior Research Methods \& Instrumentation, 12, 614-626.

Diener, D., \& SMEe, W. P. (1984). Apple tachistoscope. Behavior Research Methods, Instruments, \& Computers, 16, 540-544.

HildRETH, E. C. (1984). The measurement of visual motion. Cambridge, MA: MIT Press.

HochberG, J. E. (1978). Perception. Englewood Cliffs, NJ: Prentice-Hall.

MarR, D. (1982). Vision. San Francisco: Freeman.

NaKAYAMA, K. (1985). Biological image motion processing: A review. Vision Research, 25, 625-660.

PARKs, T. E. (1965). Post-retinal visual storage. American Journal of Psychology, 78, 145-147.

PrILL, K. A. (1984). Picture stimuli for the Apple II computer. Behavior Research Methods, Instruments, \& Computers, 16, 327-328.

Reed, A. V. (1979). Microcomputer display timing: Problems and solutions. Behavior Research Methods \& Instrumentation, 11, 572-576.

Rock, I. (1981). Anorthoscopic perception. Scientific American, 244, 145-153.

SATHER, J. F. (1983). Understanding the Apple II. Chatsworth, CA: Quality Software.

SNOdgrass, J. G., \& VANDERWART, M. A. (1980). A standardized set of 260 pictures: Norms for name agreement, image agreement, familiarity, and visual complexity. Journal of Experimental Psychology: Human Learning \& Memory, 6, 174-215.

(Revision accepted for publication December 16, 1985.) 